\title{
¿TIENE VIGENCIA LA OPCION POR EL PUEBLO COMO SUJETO EN EL "NUEVO ORDEN MUNDIAL"?
}

\section{Giulio Girardi*}

Crisis de la opción por los pobres

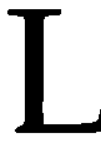

a situación actual está marcada, en gran parte de los países del mund, por un proceso aplastante de restauración capi talista, y por dramáticas derrotas, electorales, políticas, sociales, de los movimientos populares. Los casos de Nicaragua y El Salvador son particularmente significativos al respecto; pero no representan excepciones sino más bien la regla.

Ahora, analizando estas derrotas, se llega a identificar a menudo, entre sus causas principales, el hecho de que "los pobres no creen en los pobres". Es una explicación muy preocupante, porque atañe el fundamento mismo de nuestra esperanza histórica, la confianza en el papel protagónico de los pobres, y la expresión de esta confianza, la opción por los pobres como sujetos. Por tanto, una reflexión sobre el neoliberalismo y el "nuevo orden mundial", realizada en una perspectiva liberadora, no puede prescindir de esta crisis; y una de sus tareas prioritarias es la de contribuir a superarla.

Pero, ¿ qué significa aquí "nuevo orden mundial"? Con esta expresión, se designa hoy la organización política, económica y militar del mundo y la correlación de fuerzas internacionales, que se ha impuesto después del derrumbe del comunismo europeo. $\mathrm{Si}$ el antiguo orden mundial se caracterizaba como bipolar, es decir

\footnotetext{
* Filósofo y teb́logo, profesor visitante de la UCA.
} 
por el antagonismo entre capitalismo y comunismo, liberalismo y marxismo, y entre las superpotencias de los dos campos, el nuevo orden mundial se caracteriza como unipolar, es decir por el triunfo del capitalismo neoliberal y por el dominio de la única superpotencia políbico-militar, Estados Unidos.

Ahora el aspecto más mortífero del neoliberalismo y del nuevo orden mundial es justamente su capacidad de erradicar la confianza en los pobres; aún más de destruir la confianza de los propios pobres en sí mismos. Por un lado este sistema económico y político acrecenta indefinidamente el número y el sufrimiento de los pobres; por el otro los aplasta, política y sicológicamente, reduciendo cada vez más su cuota de poder y por tanto su capacidad de iniciativa y reacción. Si el sistema engendra el fatalismo y la desesperanza, es principalmente porque, al ahogar la capacidad de reacción de los pobres y de los pueblos oprimidos, destruye cualquier posibilidad de un nuevo futuro para ellos y para toda la humanidad.

Ahora, en la cultura, la espiritualidad, el compromiso de muchos cristianos, especialmente latinoamericanos, la opción por los pobres como sujetos había conquistado, en las tres últimas décadas, un lugar fundamental. El derrumbe del fundamento amenazaría seriamente la persistencia de todo el edificio : efectivamente, la crisis de la opción por los pobres conlleva a menudo una crisis de militancia y un fuerte cuestionamiento cultural y teológico. De aquí la necesidad de tomar en serio esta crisis y de analizar detenidamente sus causas.

\section{¿Porqué optar por los pobres hoy?}

$\bar{F}^{\mathrm{n}}$ los años de intensa movilización popular, marcados por un Ecierto "optimismo histórico" ( es decir por una çonfianza en el triunfo final de los oprimidos ) la opción por los pobres se impuso a la conciencia de muchos cristianos, especialmente latinoamericanos, como una evidencia primera, que no necesitaba ser fundamentada. No podemos negar que, en aquel contexto apasionado, el condicionamiento social de parte de nuestras comunidades, grupos, movimientos, organizaciones haya tenido un fuerte influjo sobre nuestras convicciones, que muchas veces no llegaron a tener una fundamentación crítica y personal. Se reflexionaba mucho en- 
tre nosotros sobre las implicaciones prácticas y teóricas de la opción por los pobres, pero pocas veces se sentía la necesidad de fundamentarla, planteando la pregunta: ¿porqué optamos por los pobres?

Ahora, esta es justamente la pregunta que nos impone la embestida neoliberal, al erosionar, día tras día, las certezas que nos habían alimentado. Propiamente, ella no cuestiona la opción por los pobres en su sentido asistencial. Al contrario, de algún modo la fortalece, por cuanto, al incrementar espantosamente el número y el sufrimiento de los pobres, estimula a las personas más sensibles a priorizar el problema de su sobrevivencia; al acentuar año tras año la expoliación y marginación de los pueblos periféricos, les impone con urgencia, a los paises ricos, el problema de la "intervención humanitaria".

Lo que el neoliberalismo cuestiona, en cambio, es la opción por los pobres y los pueblos oprimidos como sujetos históricos es decir su capacidad de convertirse en protagonistas de la historia, de oponerse a los grupos y pueblos dominantes, de conquistar su autonomía, de elaborar nuevos modelos económicos y sociales y de luchar con eficacia para realizarlos.

Una de las diferencias fundamentales entre las dos opciones, es que la primera se integra perfectamente en el nuevo orden mundial, contribuyendo, inclusive, a su estabilidad; mientras que la segunda lo cuestiona radicalmente y se impone como un llamado a la resistencia y a la búsqueda de alternativas.

La distinción entre una concepción asistencial y una participativa de la opción por los pobres, es esencial también para entender los conflictos agudos que al respecto han surgido en la iglesia católica: donde todos proclaman la opción por los pobres en su sentido asistencial; pero donde se condena el que pretende reconocer a los pobres como sujetos políticos y eclesiales y sacar las consecuencias de esta opción.

Planteándonos la pregunta, en un contexto social y mundial tan hostil, el meoliberalismo nos obliga a darle una respuesta más personal, más rigurosa y fundamentada, o bien a reconocer que no tenemos respuesta, y que nuestras antiguas certezas están seriamente sacudidas. 
Queremos entonces primero analizar la crisis de la opción para luego intentar darle una respuesta.

\section{La opción por el pueblo como sujeto: factores de la crisis}

Cómo se produce concretamente el cuestionamiento de la opción por los pobres como sujetos en el contexto actual? Algunos acontecimientos, como derrotas electorales, sociales o políticas, son a menudo el detonante de la crisis: pero sus factores fundamentales hay que buscarlos en las mismas estructuras. políticas, económicas, culturales y religiosas del nuevo orden mundial.

\section{En Nicaragua: la derrota electoral del Frente Sandinista}

F n Nicaragua, el detonante de la crisis fue para muchas persoplar que se le había reconocido a la Revolución nicaragüense le confiere a la reflexión sobre esta experiencia un valor que trasciende el caso de Nicaragua.

Los cristianos que se habían comprometido con la revolución popular sandinista, lo habían hecho a menudo porque veían en su proyecto una profunda coherencia con la opción por los pobres como sujetos. El triunfo de la revolución, de David contra Goliath, pareció una brillante confirmación de la fuerza histórica de los pobres.

Siguieron diez años apasionantes de lucha y esperanza, de conquistas y errores, de fuerte atención y solidaridad internacional. El aspecto más significativo de la experiencia fue el surgimiento fatigoso y contradictorio del pueblo nicaragüense, es decir del conjunto de los sectores populares, como sujetos políticos, económicos, culturales, eclesiales, etc.

Después vino la derrota, .Ninguna derrota electoral fue tan traumática, en Nicaragua y el mundo. Todos sentimos que no era la derrota de un partido político, sino de un gran proyecto histórico. Un proyecto que había mobilizado todo un pueblo y que, para muchos nicaragüenses, coincidía con su proyecto de vida. Un proyecto por el cual muchos habían luchado, sufrido, muerto. Un proyecto que se había impuesto a nivel mundial como "la esperanza nueva", que les había devuelto a militantes y ex-militantes el valor 
de osar y la capacidad de creer en el futuro.

Nueva correlación de fuerzas a nivel internacional

$\mathrm{H}_{\mathrm{n}}$ la crisis, colectiva y personal, provocada por este aconteciL miento, no pudo no estar involucrada la opción por el pueblo como sujeto. Los análisis de la derrota identificaron sus causas principales en la intervención directa, militar, política y económica del imperio norteamericano, que no se había resignado a la rebelión del pequeño pueblo de Nicaragua y había desencadenado todo su poderío para aplastarla. De aquí la conclusión amarga que muchos sacaron: el pueblo de Nicaragua, a pesar de su alto nivel de conciencia política y de su heroica lucha, no tiene y no tendrá nunca la fuerza necesaria para sustraerse a la dominación norteamericana y para afirmar en la práctica su derecho de autodeterminación y su soberanía. El ciclo de las luchas antimperialistas, declararon algunos líderes, se ha acabado. De lo que se trata hoy, para los pueblos pequeños, es de "convivir con el imperio", renunciando a realizarse como sujetos históricos, y abandonando definitivamente el viejo sueño de una comunidad mundial de pueblos libres y soberanos.

Esta actitud "realista" parecía impuesta también por el derrumbe del comunismo esteuropeo, que se verificaba en aquellos años y que ha golpeado fuertemente, a nivel político y económico, la confianza de los pobres y de los pueblos pequeños en sí mismos. De repente los movimientos de liberación se vieron privados de sus aliados más poderosos y se encontraron solos en el enfrentamiento con el coloso norteamericano, fortalecido por su triunfo sobre el comunismo. La nueva correlación de fuerzas pareció poner en duda definitivamente la vigencia de la lucha antimperialista.

\section{Crisis de credibilidad de las organizaciones populares}

Drofundizando el análisis, se evidenció posteriormente que la 1 derrota electoral del Frente Sandinista no había sido causada sólo por la fuerza aplastante del enemigo, sino también, en una cierta medida, por la voluntad de muchos nicaragüenses, inclusive de los sectores populares, de castigar al Frente ¿Castigarlo, por- 
qué? Porque, opinaban ellos, había traicionado la causa que fuє su razón de ser; porque había dejado de ser y de aparecer como el partido de los campesinos y de los obreros; porque el verticalismo de sus estructuras político-militares había obstaculizado el surgimiento del pueblo como sujeto, que él pretendía promover; porque la tensión ética que había inspirado su proyecto histórico y tantas de sus luchas ya no marcaba la vida y el comportamiento de sus dirigentes. Ahora, para muchos nicaragüenses la opción por los pobres en su aspecto político se había concretado en una identificación con el Frente Sandinista. Por tanto, el desprestigio del Frente repercutía inevitablemente en la crisis de la opción.

Por lo demás, una crisis de credibilidad de las organizaciones populares, particularmente de los partidos comunistas, existe a nivel internacional: ellas pues no logran hacerse reconocer por los sectores populares, obreros, campesinos, que pretenden representar. En el este europeo, el desmoronamiento del comunismo ha mostrado que las grandes mayorías ya no se sentían representadas por los partidos autodenominados "obreros". Ahora, se hace más difícil para los sectores populares creer que pueden llegar a ser sujetos cuando no perciben ninguna organización política capaz de interpretar auténticamente sus intereses y sus ideales.

\section{Mundialización de la economía y concentración del poder}

A demás, la organización actual de la economía evoluciona en dependencia tan acentuada entre los hombres y los pueblos, que conlleva el papel determinante de los agentes macroeconómicos: el club de los siete grandes, los supergrandes (Estados unidos, Japón, Alemania), los organismos financieros internacionales (Banco Mundial, Fondo Monetario Internacional), las empresas transnacionales, etc.. Además, la mundialización implica la concentración creciente del poder político, económico, informativo en pocas manos. El derrumbe del comunismo esteuropeo representa un viraje en el proceso de concentración del poder mundial, determinando el paso de un orden bipolar a un orden unipolar. Ahora ¿Cómo pueden los pobres y los pueblos periféricos en este contexto aspirar a afirmarse como sujetos? En la experiencia de Nicaragua, la gravedad de la crisis económica y el fracaso de los intentos 
para salir de ella, la contradicción flagrante entre, por un lado, los imperativos del Banco Mundial y del Fondo Monetario Internacional y, por el otro, las necesidades vitales de las grandes mayorías, parecen mostrar la imposibilidad para un país periférico, de convertirse en sujeto autónomo de su economía y por lo tanto de su historia.

En la concentración del poder económico, político y militar asumen hoy día un papel cada vez más decisivo la ciencia y la tecnología. Están llamados a ser sujetos históricos, en cada país y a nivel mundial, únicamente los que dominan el saber científico y tecnológico. En este contexto, los pobres representan los sectores atrasados de la sociedad y del mundo; por tanto constituyen más bien obstáculos al progreso que posibles protagonistas.

\section{Concentración del poder cultural, ideológico e informativo}

T a mundialización conlleva en particular la concentración del Lpoder cultural, ideológico e informativo. Las multinacionales de la información, mayoritariamente norteamericanas, dominan el sistema informativo mundial y por lo tanto tienen un influjo decisivo sobre la conciencia de las masas.

Los medios de comunicación, y particularmente la televisión, promueven a nivel masivo una actitud individualista y competitiva, inculcando una visión del éxito en la vida, que consiste en prevalecer sobre los demás, enriquecerse sin límite, tener acceso a los bienes de consumo siempre nuevos, ofrecidos por el mercado. Así los pobres asimilan los valores y las aspiraciones de los ricos, viven su condición como una continua frustración, sufren un complejo de inferioridad que les oculta los valores, las riquezas y las potencialidades de los pobres.

Asimismo, los medios de comunicación evidencian la creciente dificultad de los problemas del mundo, y ante ellos, la creciente impotencia de los pobres. Con este bombardeo cuestionan la opción por los pobres como sujetos no solamente como certeza intelectual, sino también y quizás principalmente como actitud psicológica de confianza en los sectores populares. Surge así a nivel masivo un modelo de hombre que ha interiorizado la dependencia y la marginación y la considera parte de la normalidad. 
Al poderoso aparato cultural de los grupos y pueblos dominantes se contrapone el nivel artesanal de los intentos de resistencia y concientización popular. Esta correlación de fuerzas parece condenar a los sectores concientizados del pueblo a permanecer indefinidamente minoritarios, excluyendo así la posibilidad de que lleguen a constituir una fuerza capaz de contraponerse al bloque dominante.

Por el otro lado, en muchos países, especialmente del Tercer Mundo, es la lucha cotidiana por la sobrevivencia, la que se encarga de mostrar la dificultad de los problemas y la impotencia de los pobres. Además, esta lucha propicia un clima de individualismo y de "isálvese quien pueda!". Provoca a menudo guerras entre pobres. Engendra a veces el grave fenómeno del "racismo de los pobres": por ejemplo entre nacionales y extranjeros, mestizos e indígenas, blancos y negros, norteños y sureños, entre etrias o distintos sectores de la misma etnia, etc.

\section{Restauración eclesiástica}

Zn las iglesias, especialmente en la católica, la opción por los Lobres como sujetos enfrenta el rechazo de la jerarquía, que la denuncia como "ideológica" y "marxista". Por tanto en estos años, el proceso de restauración eclesiástica, apoyando la restauración política y económica, ha condenado y marginalizado a teólogos de la liberación, a comunidades cristianas de base, a la iglesia popular, a la lectura popular de la Biblia, a movimientos cristianos inspirados por la teología de la liberación, al proyecto de evangelización liberadora elaborado por la CLAR (Confederación latinoamericana de religiosos y religiosas), etc.. La afirmación del neoliberalismo a nivel mundial procede también de que esta ideología ha logrado históricamente aliarse con el cristianismo, protestante y católico, llevando con él la lucha contra el enemigo común, el "comunismo ateo". Nicaragua es un ejemplo típico de semejante alianza. Todos estos hechos y el clima que revelan cuestionan la posibilidad de vivir coherentemente en la iglesia la opción por el pueblo como sujeto sin enfrentarse a la jerarquía; conflicto que debilita a los movimientos populares y dificulta su crecimiento.

Las iglesias institucionales, al compartir con el liberalismo el fervor de la lucha y la exaltación del triunfo contra el comunismo, 
han conquistado su espacio en el nuevo orden mundial. Por su parte, la iglesia católica, con la Encíclica Centésimus Annus le brinda al nuevo orden mundial su legitimación y se propone como su fundamento moral y espiritual. Por cierto, ante la masacre de los pobres, perpetrada por los ajustes neoliberales, las jerarquías no pueden evitar en estos años formular fuertes criticas. Sin embargo ellas golpean las desviaciones morales del sistema; pero no llegan a denunciar el carácter criminal de sus principios y de sus estructuras. El nuevo orden mundial tiene su iglesia del silencio.

Entonces, por muchos caminos el neoliberalismo aplasta a los pobres y descalifica la opción por los pobres como sujetos. De lo que se trata, es de un genocidio estructural: es decir que no consiste sólo en una muchedumbre de acciones destructoras, sino en un sistema económico, político, cultural y religioso ordenado a aplastar a los pobres y a los pueblos. Sin embargo, se trata de un genocidio oculto, porque el impacto de las estructuras parece natural, necesario y normal y su aspecto criminal queda desapercibido para las grandes mayorías.

La crisis de la opción conlleva el cuestionamiento radical de una cultura, una espiritualidad, una teología, un compromiso político, que tenían en ella su fundamento. Conlleva por tanto una crisis de la esperanza, que puede ser mortal. Para los que hemos apostado sobre los pobres como sujetos, la cuestión de su misión histórica no es académica, sino que es un problema de vida o muerte.

2. La opción por el pueblo como sujeto: resistencia y alternativa al nuevo orden mundial

Ta opción por el pueblo como sujeto ha dejado de ser para los Lcristianos una postura espontánea, favorecida per el clima cultural, político y eclesial. Ella se presenta más claramente que nunca como una toma de partido antagónica con respecto a la cultura dominante a nivel mundial. Sostenerla significa navegar contra la corriente, y defenderla día y noche contra ataques incesantes, manifiestos y ocultos. Significa también fundamentar sólidamente la posibilidad de la resistencia y de la búsqueda de alternativas al sistema de opresión y muerte. Entonces, la opción por el pueblo 
como sujeto, por firme que sea, nunca se puede considerar definitiva: tiene que ser constantemente renovada en el fuego de un combate cada vez más difícil y arriesgado.

El nuevo contexto nos impone por tanto un replanteamiento más critico y personal del problema. Esto implica primero, definir más claramente lo que significa la opción y segundo, preguntarnos si ella se justifica hoy.

\section{¿Qué significa optar por el pueblo como sujeto?}

1) Para definir el sentido de la opción por los pobres o por el pueblo como sujetos es necesario aclarar lo que se entiende aqui por "pobres" y por "pueblo". Estas palabras tienen muchos sentidos y es importante saber como las entendemos nosotros.

- "Pobres" no son sólo los que carecen de los medios económicos necesarios, sino todos los oprimidos y marginados social, política, étnica y económicamente; los que están excluidos de la libertad, la cultura y el poder. En una palabra, los que tienen intereses objetivos en conseguir un cambio del sistema social vigente. El conjunto de estos sectores oprimidos y marginados es lo que llamamos aquí "el pueblo."

- Entonces "los pobres" o " el pueblo" como sujetos no son sólo los sectores populares, sino también los componentes de la burguesía que comparten el proyecto popular de liberación. En otras palabras : "el pueblo como sujeto" es el "bloque social" constituido alrededor de este proyecto. Del bloque popular forman parte, entonces, también los intelectuales, los científicos, los técricos, los profesionales, los pequeños empresarios dispuestos a poner su cultura y competencia al servicio de la liberación del pueblo. Asimismo, forman parte de él las comunidades cristianas que se han renovado a partir de la opción por el pueblo como sujeto. Hay que tener en cuenta a todos estos componentes, cuando se habla de la fuerza histórica de los pobres.

Entonces "los pobres" y "el pueblo" así definidos son para nosotros fórmulas equivalentes. Sin embargo, preferimos aquí usar el término "pueblo" que evidencia más la dimensión colectiva y política de la opción; que, además, facilita el enlace con la categoria bíblica de "pueblo de Dios". 
- La opción por el pueblo como sujeto no puede ser políticamente significativa si se mantiene a este nivel general. En cada país, es esencial llegar a una definición concreta del pueblo: es decir, de los sectores oprimidos que lo constituyen, de sus organizaciones sociales y políticas, de sus organizaciones económicas. También es importante identificar los procesos de educación popular liberadora y de reconciliación del pueblo con el pueblo, que de formas distintas contribuyen a engendrar al pueblo como sujeto social, político, cultural y económico.

La definición del pueblo así entendido supone una constante exploración de la vida del país, con atención particular a los sectores populares y a su evolución; exploración que se desarrolle con la preocupación de descubrir los signos de esperanza y de derrotar un pesimismo paralizante.

- En el caso de Nicaragua, la exploración tiene que partir de la hipótesis que el proceso revolucionario, a pesar de sus limites, errores y derrotas, ha realizado y provocado profundas transformaciones en la vida del país, particularmente por lo que se refiere a los sectores populares, a sus niveles de conciencia, a sus formas de organización política, social, económica, cultural y eclesial. Estas son las auténticas conquistas de la revolución, que es necesario defender y fortalecer; y que representan una sólida base para relanzar en el país el proceso revolucionario.l

2) Optar por el pueblo como sujeto no significa que los sectores populares son sujetos de historia, ni que van a serlo necesariamente en el futuro; sino que pueden llegar a serlo. Que en ellos está escondido, pero realmente presente un potencial de inteligencia, sensibilidad moral, iniciativa y creatividad, que puede convertirlos en protagonistas. La misma condición de opresión y sufrimiento los dispone a percibir claramente la violencia del sistema, a solidarizarse con los que sufren, a buscar los caminos para construir entre los hombres una convivencia más justa y fraterna.

Esta presentación del pueblo les parece una idealización "populista", a los que se limitan a describir su condición actual, sin saber escrutar sus potencialidades. Porque estas riquezas se encuentran enterradas y ocultadas por todo un sistema de condicionamiento social y cultural, que les impide manifestarse. Su libera- 
ción no es algo automático ni rápido, sino que conlleva un largo proceso de concientización y educación liberadora.

Optar por los pobres como sujetos en este contexto significa entonces confiar en ellos, desafiando las apariencias y las evidencias; confiar en ellos inclusive cuando ellos no confían en sí mismos. Audacia, que sólo un amor entrañable puede inspirar.

Optar por los pobres significa comprometerse a promover en todos los sectores procesos de concientización y educación liberadora, ordenados a impulsar su maduración como sujetos. Estos procesos representan el eje de la resistencia a la presión ideológica neoliberal y el nervio de las alternativas populares al sistema opresor. Porque al tomar conciencia de sus recursos intelectuales, morales y políticos, el pueblo se anima a elaborar múltiples microalternativas; que anuncian y preparan un proyecto de alternativa global, fundado sobre el protagonismo del pueblo y de los pueblos.

3) La opción por el pueblo como sujeto impone la fidelidad hasta el fin a su proyecto histórico, pero no necesariamente a las organizaciones que pretenden realizarlo, cuando se constata que en la práctica lo han traicionado. Sin embargo, optar por el pueblo como sujeto significa comprometerse a promover y fortalecer sus organizaciones, participando, con un aporte crítico y creador en su contínua renovación. Significa luchar para que las organizaciones abandonen el vanguardismo y verticalismo, reconociendo al pueblo en la práctica y no solo en la teoría como sujeto. Significa no dejarse desanimar ni por las desviaciones ni por las derrotas; superando los resentimientos y desalientos que empujarian a abandonar las organizaciones y la misma lucha.

\title{
¿Porqué optar por el pueblo como sujeto?
}

\begin{abstract}
T a teoría marxista fundaba el compromiso con las clases popuLlares en la certeza de que el "proletariado", la clase explotada de hoy sería la vencedora de mañana. Optar por el proletariado significaba entonces tomar partido por los vencedores de mañana, caminar en el sentido de la historia. Sin embargo, las contínuas derrotas de los movimientos obreros y populares acabaron con esta certeza, provocando crisis agudas de militancia.
\end{abstract}


Nosotros al optar por el pueblo como sujeto, no nos identificamos con los vencedores de mañana sino con los oprimidos y derrotados de hoy. Optamos por el pueblo como sujeto porque reconocemos que su causa es justa; que la autodeterminación es un derecho fundamental, constitutivo de su misma identidad; que amar de un modo eficaz a todas las personas, significa comprometerse a construir una sociedad y un mundo donde el pueblo y los pueblos puedan afirmarse como sujetos.

Optamos por el pueblo como sujeto porque percibimos que el derecho y la justicia, cuando se afirman en las conciencias, se convierten en fuerzas históricas liberadoras, capaces de contraponerse al derecho de la fuerza. Porque apostamos por una alternativa de sociedad y civilización, donde la fuerza del derecho prevalezca sobre el derecho de la fuerza; lo que se verifica justamente sólo si se realiza el protagonismo del pueblo y de los pueblos.

Optamos por el pueblo como sujeto porque creemos que el triunfo de David sobre Goliath es posible; pero sin tener de ningún modo la certeza de este triunfo. La opción así entendida no puede ser desautorizada por la derrota: una causa justa derrotada no deja por esto de ser justa.

En Nicaragua, la experiencia de la derrota ha impuesto a los militantes un discemimiento de sus motivaciones. Los que habían apostado únicamente sobre el triunfo, abandonaron la lucha o se trasladaron de una vez al campo de los vencedores. Los que se habían comprometido por el valor moral y político del proyecto, reafirmaron en la derrota su fidelidad.

La opción así entendida tiene el carácter de una utopía, es decir de un ideal de sociedad radicalmente distinta a todas las existentes, y cuya misma posibilidad no es cierta; que sin embargo tiene una eficacia movilizadora, actuando como una "hipótesis histórica fecunda". Es decir, como una tensión que no está segura de poder realizar plenamente su proyecto, pero está segura de que este horizonte, este sueño, esta perspectiva es una fuente inagotable de inspiración para buscar caminos nuevos, para inventar formas de convivencia humana más solidaria y fraterna, para poner la imaginación en el poder. Digo que esta hipótesis es fecunda, en el sentido de que hay muchas cosas que no se descubrirían y por lo tanto 
no se harían, en la sociedad actual, si no se tuviera la perspectiva de poder romper las barreras del sistema capitalista.

Cabe recordar aquí una frase incisiva de Bakunin: "Es buscando lo imposible, como el hombre ha realizado siempre lo posible; y quienes se han limitado sabiamente a lo que les parecía posible, jamás avanzaron un solo paso."

La opción así entendida supone un cambio profundo en la psicología de los militantes, que por varias generaciones fueron formados a fundar su compromiso sobre la certeza del triunfo final (¡Venceremos!). La nueva psicología se alimenta en la certeza de que su causa es justa y digna; pero convive con la incerteza, la búsqueda, los tanteos, los éxitos y fracasos. Así la opción por el pueblo abre una brecha entre las certezas, que se quiebran y la desesperanza que nos amenaza.

\section{La opción por el pueblo como sujeto opción de Dios y de Jesús}

Por cierto, el valor de la opción por el pueblo como sujeto no 1 depende de la fe cristiana, sino que su evidencia se impone a toda persona concientizada. Muchos militantes ateos, particularmente marxistas, se han comprometido fundándose en ella; y han llegado a entregar la vida por la causa del pueblo. El Che Guevara ha quedado en la historia como el símbolo de esta santidad atea. La revolución popular sandinista puede indudablemente brindar muchos ejemplos semejantes.

Sin embargo, también es cierto que la opción por los pobres se ha afirmado especialmente en comunidades cristianas y que la experiencia de fe, alumbrada por la palabra de Dios ha tenido un papel decisivo en este descubrimiento. Para los cristianos que se han comprometido en la revolución motivados por la fe, resulta menos difícil, en la hora de la derrota y del desencanto, reafirmar su fidelidad al proyecto del pueblo, que coincide para ellos con el proyecto de Dios.

El fundamento último de nuestra opción por los pobres es justamente el Amor Liberador, que irrumpe en la historia de Egipto y del mundo, tomando partido por los esclavos, empujándolos a rebelarse y a movilizarse, para convertirse en sujetos de su propia historia; para construir un pueblo nuevo, libre y solidario; para 
comunicar a todo el mundo este mensaje y este dinamismo liberador. Nuestra fidelidad al Amor Liberador ya no puede separarse de la utopía que é1 le comunica al pueblo, en el momento en que se le manifiesta.

Sin embargo, al comunicarle su utopía y al provocarlo para que se comprometa a realizarla, no le garantiza el éxito histórico de la lucha. Al contrario, Dios sabe perfectamente que El mismo podrá ser derrotado con su pueblo y realmente lo será muchas veces. Pero la salida de la esclavitud de Egipto, es decir el surgimiento del pueblo como sujeto, quedará en la historia de Israel y del mundo como el acontecimiento generador, como el signo de la convergencia entre la revelación de Dios y el compromiso liberador del pueblo. En los momentos de la derrota, los profetas levantarán su voz en el pueblo, para llamarlo a rescatar, al mismo tiempo, su fidelidad al Dios Liberador y su vocación a la libertad.

Este llamado a la doble fidelidad es la esencia del mensaje y del combate de Jesús, que se manifiesta al mundo, a la par de Yavé, anunciando la liberación de los pobres. (Lc.4,16-30). Además, en la perspectiva de Jesús, como en la de Yavé, anunciar la liberación no es sólo comunicar una noticia, sino lanzar un movimiento. Cuando Jesús proclama la "Buena Nueva", cuando evangeliza, lo que pretende, como demuestra toda su práctica, es impulsar un movimiento liberador. En el centro de sus compromisos, Jesús pone un trabajo de educación del pueblo a la libertad y al amor, empujándole a rescatar la carga utópica de sus orígenes, para volver a ser efectivamente el pueblo de Yavé.

Ser discípulo de Jesús hoy día significa entonces compartir su opción por el pueblo oprimido, su proyecto de liberación, luchando hasta el fin por su realización, pero asumiendo constantemente el riesgo de la derrota. La cruz de Jesús queda en la historia como el símbolo de su identificación total con la causa de los esclavos, de su opción por los pobres, pero también como símbolo de su derrota.

La resurrección significa que, según el juicio de Dios, la causa de Jesús era justa y que su derrota no había sido definitiva; significa además, que para su lucha y la de los pobres del mundo, se abría una nueva fase y una nueva esperanza. 
La iglesia de los pobres, las comunidades cristianas de base, el cristianismo popular, la lectura popular de la Biblia, la teología de la liberación, las teologías indígenas y negras, el ecumenismo popular, el movimiento macroecuménico "asamblea del pueblo de Dios", la vida religiosa inserta, la educación popular liberadora, etc., son frutos de la opción por el pueblo como sujeto y el signo de su inagotable fecundidad. El nuevo orden mundial les plantea una nueva misión histórica: la de defender, cultivar, desarrollar este grano de mostaza, amenazado por la tormenta, que es la opción por el pueblo como sujeto, haciendo de ella la fuerza inspiradora de la resistencia y de la alternativa de civilización. Por cierto, ella "es ciertamente más pequeña que cualquier semilla, pero cuando crece es mayor que las hortalizas y se hace árbol, hasta el punto de que las aves del cielo vienen y anidan en sus ramas" (Mt.13,31-32)

Nota:

1. Es extremadamente significativo y esperanzador, bajo este punto de vista, el artículo de Orlando Nuñez Soto, Una nueva utopía sandinista en Envfo Junio 1994, pp.15-20. 